\title{
A TRIBUTAÇÃO NA PANDEMIA: O RESPEITO AO PRINCÍPIO DA CAPACIDADE CONTRIBUTIVA
}

\author{
Saul Baldivieso ${ }^{1}$ \\ Pablo Baldivieso ${ }^{2}$
}

Resumo: O presente artigo tem por finalidade analisar os principais efeitos da pandemia na tributação brasileira, tendo como destaque o princípio constitucional da capacidade contributiva. $\mathrm{O}$ artigo traz como problema central, o seguinte questionamento: como a pandemia pode afetar a capacidade contributiva das pessoas? Partindo deste problema, desenvolve-se a seguinte hipótese: O Estado deve respeitar a capacidade contributiva das pessoas levando em consideração a retração econômica causada pela pandemia. Assim, serão abordados os efeitos da pandemia no campo da tributação tendo em vista o princípio da capacidade contributiva e qual o papel do judiciário sobre este aspecto.

Palavras-chave: Tributação; Covid; Princípio Constitucional da Capacidade Contributiva; Intervenção do Poder Judiciário; Repercussões das decisões judiciais.

\section{TAXATION IN PANDEMIC: RESPECTING THE PRINCIPLE OF CONTRIBUTIVE CAPACITY}

Abstract: The purpose of this article is to analyze the main effects of the pandemic on Brazilian taxation, highlighting the constitutional principle of contributory capacity. The article poses as a central problem, the following question: how can the pandemic affect people's ability to contribute? Based on this problem, the following hypothesis is developed: The State must respect people's contributory capacity, taking into account the economic downturn caused by the pandemic. Thus, the effects of the pandemic field of taxation will be addressed, taking into account the principle of contributory capacity and what is the role of the judiciary on this aspect.

Key-Words: Taxation; Covid; Constitutional Principle of Contributory Capacity; Intervention by the Judiciary; Repercussions of judicial decisions.

\section{INTRODUÇÃO}

Em 20 de março de 2020 foi publicado o Decreto- Legislativo $n^{\circ} 6$ de $2020^{3}$ que introduziu o

\footnotetext{
${ }^{1}$ Mestrando em Direito, Governança e Políticas Públicas pela Universidade Salvador-UNIFACS. Especialista em Direito Público e Especialista em Ciências Criminais. Procurador Legislativo da Câmara Municipal de SerrinhaBahia. Advogado. Procurador da União de Vereadores do Estado da Bahia. Ex-Juiz Leigo dos Juizados Especiais do Estado da Bahia. Ex-Procurador Geral do Município de Serrinha-Bahia.*saulbaldivieso@ @otmail.com, Rua Demétrio Couto Guerrieri, 622, Centro, Eunápolis-BA.

${ }^{2}$ Doutor em Direito UFBA; Mestre em Direito UCB. Juiz Federal.*pablobaldivieso1@gmail.com, Rua Demétrio Couto Guerrieri, 622, Centro, Eunápolis-BA.

${ }^{3}$ BRASIL, Planalto, Decreto- Legislativo no 6 de 2020, Reconhece o Estado de Calamidade Pública. Disponível em: http://www.planalto.gov.br/ccivil_03/portaria/DLG6-2020.htm. Acesso em: 01 setembro de 2020.
} 
chamado marco pandêmico no Brasil, estabelecendo do dia 20 de março de 2020 até o dia 31 de dezembro de 2020, a ocorrência do Estado de calamidade pública no Brasil. É muito natural que em razão da pandemia diversos setores econômicos e toda humanidade tenham sido afetados por uma pandemia de proporções catastróficas, prejudicando diversas atividades do Estado.

No presente trabalho, o recorte metodológico será feito tão somente levando em consideração os efeitos do Covid-19 no campo da tributação. Para isso, o Tribunal de Constas da União-TCU, extraiu importante relatório, onde faz uma análise pormenorizada dos efeitos nefastos provocados pela pandemia na seara de tributação no Estado brasileiro. Trata-se do Relatório de acompanhamento $\mathrm{n}^{\mathrm{o}}$ TC $016.841 / 2020-4^{4}$, onde o TCU faz criteriosa avaliação do impacto causado pelo Covid-19 na arrecadação tributária federal.

O TCU classificou que foram tomadas três tipos de medidas em face da pandemia, que seriam: desonerações tributárias, diferimentos no pagamento de tributos e medidas de desburocratização de responsabilidades tributárias, página 1 do relatório do TCU.

Um dos principais efeitos da pandemia na tributação consistiu na queda da arrecadação dos tributos federais. Segundo dados do relatório do TCU do total da arrecadação administrada pela RFB prevista na LOA até o mês de junho estava prevista uma arrecadação de R \$ 765,678 bilhões, mas o montante efetivamente arrecadado foi de $\mathrm{R} \$ 637,217$ bilhões, o que representa a frustração das receitas inicialmente previstas em $\mathrm{R} \$ 128,461$ bilhões, pág. 10 do relatório.

O olhar na esfera tributária deve ser feito sob o prisma da anormalidade, uma vez que a pandemia alterou de maneira significativa todos os setores da economia. A relação entre excepcionalidade e tributação não é estranha ao ordenamento jurídico brasileiro, pois a própria Constituição brasileira tratou, em alguns dispositivos, da hipótese de criação de tributos expressionais, conforme se afere da possibilidade de criação do empréstimo compulsório, artigo 148, inciso I, da CRFB, em caso de calamidade pública e ainda na possibilidade de instituição de impostos residuais, no caso de iminência de guerra externa, vide artigo 154, inciso II, da CRFB.

${ }^{4}$ BRASIL, Tribunal de Contas da União, Relatório de Acompanhamento no TC 016.841/2020-4, Acompanhamento especial das medidas de resposta à crise do coronavírus na arrecadação tributária e previdenciária federal. Disponível em:https://pesquisa.apps.tcu.gov.br/\#/documento/acordaocompleto/1684120204.Acesso em 01 setembro de 2020. 
Há, inclusive, Projeto de Lei Complementar de $n^{\circ} 34 / 2020^{5}$, que instituí Empréstimo Compulsório visando atender às despesas urgentes causadas pela situação de calamidade pública relacionada ao coronavírus (COVID-19). De acordo com o artigo $2^{\circ}$ do Projeto de Lei, pessoas jurídicas domiciliadas no país, com patrimônio liquido igual ou superior a $\mathrm{R} \$ 1.000 .000 .000,00$ (um bilhão de reais), ficam sujeita a cobrança de $10 \%$ (dez) por cento do lucro líquido apurado nos doze meses anteriores à publicação da Lei.

Na justificativa do Projeto de Lei, de autoria do Deputado Wellington Roberto, existe a hipótese de ocorrência de gastos superiores ao que foi previsto com medidas de contenção a pandemia. $\mathrm{O}$ Projeto encontra-se em tramitação na Câmara dos Deputados. De fato, a situação de calamidade pública, implica não só numa queda na arrecadação de receitas, conforme visto, como também, num aumento de despesas em função dos gastos públicos necessários ao combate da doença.

A queda na arrecadação demonstra que a pandemia afetou a situação econômica das pessoas, pois a circulação de bens, serviços e pessoas ficou extremamente restrita. Neste ponto, apontam-se dois princípios extremamente importantes para esse contexto que são o princípio constitucional da capacidade contributiva, previsto no artigo $145, \S 1^{\circ}$, da CRFB e a função social da empresa, previsto no artigo 170 , inciso III da CRFB.

O principal problema a ser abordado é justamente como a capacidade contributiva foi afetada pela pandemia? Partindo deste problema, como o Judiciário deve pautar suas atuações em situações excepcionais em que a pessoa solicita a intervenção deste Poder em conjunturas em que não há possibilidade de pagamento ou mesmo em cenários em que a própria vida da empresa ou da pessoa está em jogo.

Com efeito, o princípio da capacidade contributiva, embora mereça crítica da doutrina ${ }^{6}$ nacional em razão de sua vaguidão, tal crítica não retira em nenhum momento a força normativa que este princípio exerce sobre o ordenamento jurídico, principalmente quando o mesmo é preenchido pela interpretação concreta do princípio frente a situações reais.

5 BRASIL, Câmara dos Deputados, Projeto de Lei Complementar de $\mathbf{n}^{\circ}$ 34/, Disponível em: https://www.camara.leg.br/proposicoesWeb/prop_mostrarintegra;jsessionid=10E1BF8BF4B475146373026775F4331 B.proposicoesWebExterno1?codteor=1869953\&filename=PLP+34/2020. Acesso em 04 setembro de 2020.

${ }^{6}$ BECKER, Alfredo Augusto. Teoria geral do direito tributário. 2.ed. São Paulo: Saraiva, 1972, p.439. 
O saudoso doutrinador Antônio Roberto Sampaio Dória", em sua obra "Direito Constitucional Tributário e Due Process of Law", já mencionava a possibilidade de controle por parte do Poder Judiciário no momento de aferir a capacidade contributiva objetiva ao mencionar que: "a existência de riquezas suscetíveis de se tributarem é fato objetivamente apurável e com grande facilidade poderá o judiciário concluir dos desvios legislativos deste setor”.

Contudo, a priori, não cabe ao Poder Judiciário, à concessão de poder discricionário de estabelecer o quantum necessário ao pagamento dos tributos, sob pena de substituir o Legislador neste mister. Todavia, veremos que em situações específicas, é possível a utilização do princípio da capacidade contributiva, para estabelecer uma cobrança mais racional e ainda proteger o individuo de tributações extremamente onerosas.

Há ainda o princípio da função social da empresa, previsto no artigo 170, inciso III, da Constituição Federal, que busca tutelar justamente a atividade econômica desenvolvida por diversas sociedades em desenvolvimento no país. A pandemia afetou de maneira negativa diversos setores econômicos no Brasil e no mundo.

De acordo com dados do Instituto Brasileiro de Geografia e Estatística-IBGE ${ }^{8}, 37,5$ \% (trinta e sete por cento), das empresas em funcionamento no Brasil, reportaram que a pandemia teve um efeito negativo sobre a atividade empresarial. Os dados foram colhidos até a segunda quinzena de julho de 2020.

Diante deste contexto, o princípio da capacidade contributiva se mostra essencial para limitar e proteger todas as pessoas, que, diante de uma situação de vulnerabilidade econômica podem não ter condições de honrar a carga tributária imposta pelo Estado da maneira que vinha ocorrendo antes do marco pandêmico. Entretanto, cabe inicialmente ao Poder Legislativo, o múnus de determinar qual será a carga tributária que deve recair sobre a sociedade levando em consideração toda essa retração na economia.

${ }^{7}$ DÓRIA, Antônio Roberto Sampaio. Direito constitucional tributário e “due process of law". Rio de Janeiro: Forense, 1986, p. 182.

${ }^{8}$ BRASIL, IBGE, indicadores de empresas, Disponível em: https://covid19.ibge.gov.br/pulso-empresa/. Acesso em 04 de setembro de 2020 . 
Por este motivo, parcela da doutrina ${ }^{9}$, nomina a exigência da legalidade como princípio da determinabilidade, justamente por ter a função de retirar da administração e do Poder Judiciário qualquer papel no estabelecimento essencial da carga exercida pelos tributos.

Nada obstante, a pandemia inaugura uma situação completamente incomum para o campo da tributação, o que implica dizer que em situações de anormalidade, também o tratamento no campo tributário deverá se pautar em situações de excepcionalidade.

No próximo tópico será feito um panorama da tributação em face da pandemia.

\section{TRIBUTAÇÃO EM TEMPOS DE COVID-19}

A situação excepcional criada pela pandemia trouxe questões complexas para o campo do direito tributário. Por isso, é imperioso descrever como o direito tributário deve se comportar para solucionar questões extraordinárias em razão das repercussões ocasionadas pela pandemia.

Nestas plagas, em âmbito federal ${ }^{10}$, foram tomadas diversas medidas no campo tributário visando dar um tratamento diferenciado ao período completamente excepcional que toda sociedade passa atualmente. Os órgãos que compõe parte tributação federal, a exemplo da Receita Federal do Brasil-RFB, Procuradoria Geral da Fazenda Nacional-PGFN e o Conselho de Recurso FiscaisCARF, adotaram algumas medidas visando combater a pandemia.

Podemos citar como exemplos, de acordo com o relatório extraído pelo TCU: desonerações tributárias, como a redução da alíquota do IPI a zero, para os termômetros digitais, isenções do IOF nas operações de crédito da conta COVID e diferimentos que consistiram em adiamentos, suspensões e prorrogações que tem como escopo sustar ou diferir o pagamento de tributos federais, em suas diversas modalidades.

Foram tomadas, ainda, medidas de desburocratização, como simplificação do fluxo de informações de faturamento entre a RFB e a rede bancária, facilitando os procedimentos de obtenção de crédito pelas pequenas e microempresas. Outra medida importante é a referente ao

\footnotetext{
${ }^{9}$ ANDRADE, José Carlos Vieira de. Direito administrativo e fiscal. Coimbra: Faculdade de Direito, 1995 , p. 17.

${ }^{10}$ BRASIL, Tribunal de Contas da União, Relatório de Acompanhamento no TC 016.841/2020-4, Ibidem, p.2.
} 
CARF, que teve um acréscimo de $100 \%$ na sua produtividade nos julgamentos em relação às sessões presenciais, pois foram instituídas às sessões virtuais de julgamento conforme demonstração na página 5 do relatório do TCU.

Outra medida adotada pela administração tributária entre os meses de junho e julho do corrente ano, para enfretamento da pandemia do COVID-19, destaca-se a regulamentação pela RFB do Pronampe. O intuito do programa é beneficiar aproximadamente 4,5 milhões de pequenos negócios.

O Pronampe tem o objetivo de auxiliar as micro e pequenas empresas com a concessão de empréstimos, baseando-se no histórico de faturamento. Com essa medida, segundo dados do TCU, a União aumentou a participação no Fundo Garantidor de Operações em R \$ 15,9 (quinze bilhões), conforme dispõe o art. $6^{\circ}$ da Lei 13.999 de 18/05/2020, que institui o programa.

O programa destina-se a reduzir o risco de crédito dos bancos nas operações com as micro e pequenas empresas, o que torna o crédito mais acessível. A proteção dessas empresas é relevante para o governo federal para impactar na velocidade da retomada da atividade econômica quando do enfraquecimento da epidemia.

Diante de todas as medidas adotadas pelo governo federal, segundo dados do TCU, a arrecadação tributária de 2020 foi afetada pelo coronavírus. Até o mês de maio de 2020, a tendência de queda permaneceu, com leve aumento da arrecadação total de maio ( $\mathrm{R} \$ 77,42$ bilhões) para junho ( $\mathrm{R}$ \$ 86,26 bilhões), mas ainda inferior à arrecadação de janeiro de 2020 (R \$ 174,99 bilhões), aos mesmos meses em 2019, descontado o IPCA (R \$ 115,41 bilhões em maio de 2019 e R \$119,95 bilhões em junho de 2019) e aos montantes previstos na Lei Orçamentária Anual, página 9 do relatório.

O total da arrecadação administrada pela RFB prevista na LOA até o mês de junho totalizava $\mathrm{R} \$ 765,678$ bilhões, mas o montante efetivamente arrecadado foi de $\mathrm{R} \$ 637,217$ bilhões, o que representa a frustração das receitas inicialmente previstas em $\mathrm{R} \$ 128,461$ bilhões. Comparando-se a arrecadação de 2020 com o mesmo período de 2019, a arrecadação total das receitas federais em junho de 2020 totalizou R \$ 86,258 bilhões, representando um decréscimo real de 29,59\% em relação a 2019, página 11 do relatório. 
Como se vê dos dados apresentados pelo relatório do TCU, a queda da arrecadação no plano federal ocorreu em virtude da retração econômica provocada pelo COVID-19. Dentre as medidas adotadas, muitas serão substituídas com o tempo, uma vez que sua característica é a excepcionalidade, como nos casos de diferimento de tributos e as situações de desoneração.

Porém, algumas situações, mesmo diante da possibilidade de inexistência da pandemia no futuro, poderão ser consideradas permanentes, seja porque trazem benefícios para sociedade, seja porque a quebra de paradigmas, em função da crise pandêmica, trouxeram novas reflexões para toda a sociedade mundial.

Podemos citar algumas medidas implementadas que, embora temporárias, poderão ser acatadas de maneira permanente e independentemente de a pandemia continuar. As permanências de medidas antes adotadas num contexto incomum vieram para permanecer.

Dentre as medidas que poderão ser adotadas de maneira permanente têm-se as medidas administrativas de desburocratização, como por exemplo, os julgamentos virtuais inaugurados pelo CARF, assim como todo e qualquer tipo de medida administrativa tendente a conferir celeridade aos processos fiscais dos contribuintes. Os julgamentos virtuais não só economizam tempo, mas recursos públicos na atividade administrativa.

Ou seja, a pandemia impôs reflexões permanentes também no campo tributário. E neste momento, surge para o Estado um dever de contribuir para com a sociedade diante de um cenário tão devastador e recessivo para as pessoas. É preciso evoluir como nação e como administração.

Diante do contexto da pós-modernidade, o tributo estará em constante evolução, de acordo com a opção de Estado acolhido por determinado sistema constitucional nacional. Neste aspecto, revelase importante mencionar que o desenvolvimento do tributo está ligado ao desenvolvimento dos direitos fundamentais ${ }^{11}$.

Há uma preocupação crescente na relação existente entre o direito tributário e a economia, porque o tributo é verdadeira forma de intervenção do Estado no patrimônio do indivíduo e por consequência na economia. A carga tributária pode influenciar, por exemplo, a forma como as relações de trabalho são realizadas em determinados países e ainda a própria formação da

${ }^{11}$ NOGUEIRA, Alberto. Viagem ao terceiro milênio: justiça, globalização, direitos humanos e tributação. Rio de Janeiro: Renovar, 2001, p.333-338. 
sociedade ${ }^{12}$.

Sobre os ideais de tributação justa compreendem-se que a capacidade contributiva deve exprimir sempre um limite na forma como o Estado cobra das pessoas os tributos. Sempre que for possível, o Estado deve lançar meios de identificar a capacidade econômica de cada um, evitando-se que pessoas que não tenham qualquer capacidade de ganho possam ser oneradas além do limite devido.

A Capacidade Contributiva, em um mundo globalizado, serve não só ao propósito de impor um limite à tributação desenfreada, mas ainda, como forma de estimular o desenvolvimento social e reduzir as desigualdades sociais ${ }^{13}$.

No processo de globalização as noções de empresas nacionais cedem espaço a um novo tipo sociedade que estende sua influência de um contexto local para um âmbito global, fazendo ainda com que se flexibilizem as noções de soberania ${ }^{14}$.

Este contexto global está cada mais presente diante de problemas sociais e sanitários ocasionados pela pandemia, principalmente porque o combate e enfretamento de crises globais deve ser feita de maneira uniforme, por todo o mundo, reforçando ainda mais a importância do princípio da capacidade contributiva.

No próximo ponto será abordado como a imposição tributária se comporta diante da ausência de capacidade contributiva, especialmente em razão da crise financeira vivenciada pela pandemia.

\section{A IMPOSIÇÃO TRIBUTÁRIA DIANTE DA AUSÊNCIA DE CAPACIDADE CONTRIBUTIVA}

A maior parte dos recursos públicos o Estado aufere por meio de sua potestade tributária, haja vista que se utiliza de seu poder ou atributo para transferir compulsoriamente o patrimônio do particular para o Estado, tudo com o escopo de cumprir uma série de necessidades públicas ${ }^{15}$.

\footnotetext{
${ }^{12}$ TIPKE, Klaus. Moral tributaria del estado e de lós contribuyentes. Madrid: Marcial Pons, 2002, p.27.

${ }^{13}$ CARRAZZA, Roque Antônio. Imposto sobre a renda: perfil constitucional e temas específicos. 2. ed. São Paulo: Malheiros, 2006, p.313.

14 SANTOS, Boaventura de Sousa. Por uma concepção multicultural de direitos humanos. Rio de Janeiro: Civilização Brasileira, 2003, p.433.

${ }^{15}$ BRITO, Edvaldo Pereira de. Capacidade contributiva. In: MARTINS, Ives Gandra da Silva (coord.). Caderno de
} 
A potestade tributária mencionada acima foi bem delineada pelos americanos no caso julgado pela Suprema Corte dos EUA pelo juiz John Marshall, McCulloch v. Maryland, de 1819, onde se concluiu pela celebre frase: "o poder de tributar envolve o poder de destruir”. Tal orientação, posteriormente foi substituída, pela própria Suprema Corte Americana, uma vez que o tributo não pode ser visto como meio de destruir direitos fundamentais dos indivíduos.

Bem visto o panorama atual a respeito da pandemia no Brasil, percebe-se claramente que diversos setores econômicos foram atingidos em cheio pela crise sanitária. Tal situação excepcional, merece ser vista com cautela, posto que muitas pessoas deixaram de auferir receitas diante das medidas de isolamento.

Diante da ausência de capacidade de pagamento das pessoas, como deve ser comportar o Poder Fiscal? Tal fato ainda é agravado, porque o Estado também precisa de receitas, especialmente por meio dos tributos, para cumprir uma série de finalidades sociais e garantir o cumprimento dos direitos fundamentais.

O direito tributário, diferentemente de outros ramos jurídicos, não pode ser visto num contexto essencialmente civilista, posto que a relação tributária além de ser específica, visa também efetivar direitos fundamentais postos na Constituição. Logo, se todos deixassem de pagar tributos haveria um caos social muito grande, intensificando ainda mais a situação de crise.

Desta forma, para cumprir o papel de extração de recursos, o Estado encontra limites no ordenamento jurídico. As limitações conformam o sistema tributário de uma nação e em regra são estabelecidas por meio de limitações constitucionais ao poder de tributar.

O sistema só encontra legitimidade quando observa e respeita os mais elementares direitos fundamentais das pessoas. $\mathrm{Na}$ atual Carta Constitucional brasileira, essa legitimidade deve observância ao postulado basilar da dignidade da pessoa humana e do regime Democrático de Direito, nos termos do art. $1^{\circ}$, caput da Carta da República Brasileira ${ }^{16}$.

O tributo é instituto de forte intervenção do Estado no direito fundamental de propriedade do

Pesquisas Tributárias. São Paulo: Resenha Tributária, 1989, p.321.

${ }^{16}$ JUNIOR, Edilson Pereira Nobre. Princípio constitucional da capacidade contributiva. Porto Alegre: Sergio Antonio Fabris, 2001, p.13. 
indivíduo. Entretanto, é preciso que se tenha em mente que a carga tributária, necessária às satisfações públicas do Estado, não pode aniquilar o direito de propriedade das pessoas.

Neste caso, se em uma dada situação concreta se a pessoa demonstrar que não possui qualquer capacidade contributiva de pagamento, o Estado não poderá cobrar do indivíduo qualquer tributo, sob pena de ofensa ao princípio constitucional da capacidade contributiva.

O próprio conceito de capacidade contributiva, descrito pelo professor Sacha Calmon Navarro Coelho $^{17}$, deixa clara a relação da capacidade contributiva, com o princípio da dignidade da pessoa humana. Para o autor, a capacidade contributiva apresenta duas almas éticas que estão no cerne do Estado de Direito:

a) em primeiro lugar afirma a supremacia do ser humano e de suas organizações em face do Poder de tributar do Estado; b) em segundo lugar obriga os Poderes do Estado, mormente o Legislativo e o Judiciário, sob a égide da Constituição, a realizarem o valor da justiça, através da realização do valor da igualdade, que no campo tributário só pode efetivar-se pela prática do princípio da capacidade contributiva e de suas técnicas.

A dignidade da pessoa humana juntamente com o princípio da capacidade contributiva, serve ao direito fundamental das pessoas em deixar livre da Potestade tributária o mínimo para subsistência do indivíduo e capacidade contributiva evitaria que os tributos ultrapassassem o limite máximo, tornando a tributação extremamente sufocante.

Diante deste contexto, o princípio da capacidade contributiva, previsto expressamente no artigo $145, \S 1^{\circ}$ da Constituição Federal, deve ser avaliado com cautela tanto nas medidas legislativas e normativas a serem implementadas, diante da crise imposta pelo Covid-19, como ainda pelas políticas públicas que estão sendo implantadas pelo Poder Executivo diante do cenário de recessão econômica.

Alguns institutos tributários podem ajudar no combate à crise fiscal, são eles a transação tributária, a remissão e a moratória. A remissão tributária é forma de extinção do crédito tributário e está prevista expressamente no artigo 156, inciso IV, do Código Tributário Nacional-CTN ${ }^{18}$.

${ }^{17}$ COÊLHO, Sacha Calmon Navarro. Curso de direito tributário. 7. ed. Rio de Janeiro: Forense, 2004 , p. 85.

${ }^{18}$ BRASIL, Planalto, Lei $\mathbf{n}^{\mathbf{0}} \mathbf{5 . 1 7 2 / 6 6}$ (Código Tributário Nacional), disponível em: http://www.planalto.gov.br/ccivil_03/leis/15172compilado.htm, acesso em 09/09/2020. 
A remissão pode ser adotada como forma de perdoar aqueles devedores que estão em situação econômica extremamente difícil, diante da crise sanitária. É evidente que a remissão deve ser concedida somente em casos singulares e mediante Lei autorizativa, devidamente aprovada pelo parlamento brasileiro.

Registra-se que no plano federal ainda não há, ao menos até a elaboração deste artigo, ato normativo no plano federal que tenha concedido remissão de débitos tributários no âmbito da União. O artigo 172, inciso I do $\mathrm{CTN}^{19}$, prevê a hipótese de remissão de débitos tributários nos casos em que a situação econômica do sujeito passivo esteja em dificuldades.

A moratória é forma de suspensão do crédito tributário e é também prevista no artigo 151, inciso I, do CTN. Este instituto é o que tem sido mais utilizado pelo governo federal, conforme visto pelo relatório do TCU. As formas de diferimento de tributos federais vão de parcelamentos a prorrogação de prazos de pagamentos.

Contudo, a grande novidade na seara tributária ficou por conta da transação tributária instituída pela Lei $\mathrm{n}^{\mathrm{o}} 13.988 / 2020^{20}$. Tal norma somente se aplica aos débitos fiscais federais e também mereceu regulamentação no âmbito da PGFN, por meio das portarias Portarias PGFN n ${ }^{\circ} 9.917^{21} \mathrm{e}$ $\mathrm{n}^{\circ} 9.924$ de $2020^{22}$.

A Lei da transação tributária afirma que devem ser observados os seguintes princípios na aplicação da norma: isonomia, da capacidade contributiva, da transparência, da moralidade, da razoável duração dos processos e da eficiência e, resguardadas as informações protegidas por sigilo, o princípio da publicidade.

Fica claro do texto da Lei ${ }^{\circ}$ 13.988/2020 que há um objetivo claro do fisco federal em diminuir o estoque da dívida ativa da união, proporcionando uma maior eficiência na recuperação do crédito

\footnotetext{
${ }^{19}$ Ibidem, p.9, Art. 172. A lei pode autorizar a autoridade administrativa a conceder, por despacho fundamentado, remissão total ou parcial do crédito tributário, atendendo: I - à situação econômica do sujeito passivo.

${ }^{20}$ BRASIL, Planalto, Lei $\mathbf{n}^{\mathbf{0}} \mathbf{1 3 . 9 8 8 / 2 0 2 0}$ (Lei de Transação Tributária), disponível em: http://www.planalto.gov.br/ccivil_03/_ato2019-2022/2020/lei/113988.htm, acesso em 09/09/2020.

${ }^{21}$ BRASIL, Planalto, Portaria PGFN no 9.917/2020 (Regulamenta a transação na cobrança da dívida ativa da União), disponível em: http://normas.receita.fazenda.gov.br/sijut2consulta/link.action?visao=anotado\&idAto=108608, acesso em 09/09/2020.

${ }^{22}$ BRASIL, Planalto, Portaria PGFN n ${ }^{\mathbf{0}}$ 9.924/2020 (Regulamenta a transação extraordinária na cobrança da dívida ativa da União, em função da pandemia causada pelo coronavirus), disponível em: http://normas.receita.fazenda.gov.br/sijut2consulta/link.action?visao=anotado\&idAto=108609.
} 
fiscal. A transação é instituto de origem civilista, pois nela as partes abrem mão de algumas vantagens em prol de um consenso ${ }^{23}$.

Porém, se no direito civil o instituto de transação merece um tratamento jurídico regido pelo Código Civil, ou seja, no sentido de sua natureza contratual, no Direito Tributário a natureza jurídica da transação ainda é controvertida.

Para o saudoso baiano Aliomar Baleeiro, refutando a natureza civilista do instituto para o Direito Tributário, o mesmo rejeitava a natureza contratual do instituto, mas sim de ato jurídico, posto que o mesmo não criava obrigações, mas apenas extinguia a mesma. Contudo, o próprio autor faz a ressalva de que existem opiniões em sentido contrário ${ }^{24}$.

No Código Tributário Nacional a transação está prevista no artigo 156, inciso III do CTN, como forma de extinção do crédito tributário. Dentre as formas de transação, o artigo $2^{\circ}$ da Lei $n^{\circ}$ $13.988 / 2020^{25}$, menciona a possibilidade de a transação vir a ser firmada por meio de proposta individual ou por adesão.

A portaria PGFN n ${ }^{\circ} 9.917 / 2020^{26}$, estabelece ainda a possibilidade de o devedor oferecer uma proposta de transação ao fisco federal. Há também, no artigo $5^{\circ}$ da norma, a obrigação do fisco federal mensurar a capacidade de pagamento do devedor como forma de calcular a forma e modo

${ }^{23}$ RODRIGUES, Silvio, Direito civil: dos contratos e das declarações unilaterais da vontade. São Paulo: Saraiva, 2004, v. 3, p. 368.

${ }^{24}$ BALEEIRO, Aliomar. Direito Tributário Brasileiro. 12. ed. rev., atual. e ampl. (atualizada por MisabelAbreu Machado Derzi). Rio de Janeiro: Forense, 2013, p. 1324-1325.

${ }^{25}$ Ibidem, p.10, Art. $2^{\circ}$ Para fins desta Lei, são modalidades de transação as realizadas: I - por proposta individual ou por adesão, na cobrança de créditos inscritos na dívida ativa da União, de suas autarquias e fundações públicas, ou na cobrança de créditos que seja competência da Procuradoria-Geral da União; II - por adesão, nos demais casos de contencioso judicial ou administrativo tributário; e III - por adesão, no contencioso tributário de pequeno valor. Parágrafo único. A transação por adesão implica aceitação pelo devedor de todas as condições fixadas no edital que a propõe.

${ }^{26}$ Ibidem, p.10, Art. $4^{\circ}$ São modalidades de transação na cobrança da dívida ativa da União: I - transação por adesão à proposta da Procuradoria-Geral da Fazenda Nacional; II - transação individual proposta pela Procuradoria-Geral da Fazenda Nacional;III - transação individual proposta pelo devedor inscrito em dívida ativa da União;§ $1^{\circ}$ A transação de débitos inscritos em dívida ativa da União cujo valor consolidado seja igual ou inferior a R $\$ 15.000 .000,00$ (quinze milhões de reais) será realizada exclusivamente por adesão à proposta da Procuradoria-Geral da Fazenda Nacional, sendo autorizado, nesses casos, o não conhecimento de propostas individuais. $\S 2^{\circ} \mathrm{O}$ limite de que trata o parágrafo anterior será calculado considerando o somatório de todas as inscrições do devedor elegíveis à transação, observados os critérios do respectivo edital. $\S 3^{\circ}$ Quando o somatório das inscrições elegíveis ultrapassar o limite de que trata o parágrafo primeiro, somente será permitida a transação individual. 
como o sujeito passivo vai efetuar o pagamento dos débitos inscritos em dívida ativa da União.

Com efeito, como a norma descreveu a possibilidade de contribuinte aderir ou não a proposta individual feita pelo fisco, tal fato corrobora a tese da natureza contratual do instituto ao menos na situação de proposta individual.

A transação quando realizada nos autos do processo judicial de cobrança constitui verdadeiro negócio jurídico processual, posto que as partes poderão, nos termo do artigo $9^{\circ}$, parágrafo único da portaria PGFN nº 9.917/2020, convencionar a suspensão do processo, justamente visando formalizar a transação fiscal.

A possibilidade de constituição de negócios jurídicos processuais no âmbito do contencioso judicial tributário reforça que diante de situações excepcionais será possível obter a máxima satisfação do crédito tributário, sem prejuízo da análise individual de cada caso concreto, visando compatibilizar a cobrança fiscal com os direitos fundamentais das pessoas, especificamente, durante o período de crise pandêmica que assola o mundo e o Brasil em especial.

Para isso, ao menos no contencioso judicial, a possibilidade de constituição de negócios processuais em matéria tributária ganhou reforço com o artigo $190^{27}$, caput, do CPC, que embora não seja inédito no direito processual, conforme aponta professor Pedro Henrique Nogueira ${ }^{28}$, é sim uma grande novidade no direito processual brasileiro, pois conferiu as partes e aos sujeitos em geral, a forma, de disciplinarem, por meio de convenções, de maneira ampla, o próprio processo.

Mas, se existe espaço para resolver os conflitos de maneira não contenciosa, que é o que se espera nessa quadra de século, ainda é possível que a parte de tenha que recorrer ao Poder Judiciário, em situações em que sua capacidade de pagamento ficou completamente restringida diante da crise sanitária.

No próximo ponto será abordado como o Poder Judiciário tem compreendido essas questões e o que se espera deste Poder diante de uma tributação em tempos de pandemia.

\footnotetext{
${ }^{27}$ Art. 190. Versando o processo sobre direitos que admitam autocomposição, é lícito às partes plenamente capazes estipular mudanças no procedimento para ajustá-lo às especificidades da causa e convencionar sobre os seus ônus, poderes, faculdades e deveres processuais, antes ou durante o processo.

${ }^{28}$ NOGUEIRA, Pedro Henrique, Negócios jurídicos processuais, Salvador-Ba, 2016, Ed. Juspodvm, p.225.
} 


\section{O PAPEL DO PODER JUDICIÁRIO.}

Muitas são as demandas que têm sido propostas ao Poder Judiciário, no que diz respeito às relações jurídicas tributárias afetadas pela pandemia. Os principais questionamentos estão por conta das dificuldades no pagamento de tributos, acima de tudo, pela retração da economia e pela perda de receita por parte das empresas e das pessoas.

No âmbito dos tributos federais, muitas ações foram proposta visando suspender os pagamentos dos tributos federais. No âmbito do Tribunal Regional Federal da Terceira Região, tem prevalecido a orientação pelo indeferimento do pedido de suspensão dos tributos federais.

Como exemplo deste entendimento da Terceira Região, cita-se o agravo de instrumento de $\mathrm{n}^{\circ}$ 5009320-66.2020.4.03.0000 ${ }^{29}$, julgado pela terceira Turma da Corte Regional, em que o Tribunal compreendeu que a moratória prevista no art. 152 do CTN, é modalidade de suspensão de exigibilidade do crédito tributário, que depende de lei, a qual tratará dos requisitos para concessão.

Logo, não obstante a grave situação de calamidade pública em que se encontra o país e o mundo em razão da pandemia de COVID-19, a qual não é ignorada pelo Poder Judiciário, é importante consignar que não cabe a este, substituir os demais Poderes da República, intervindo, por meio de decisões individuais e episódicas, na concessão de moratórias sem observância dos princípios constitucionais, notadamente o da legalidade e o da própria separação dos poderes.

Em sentido parecido, o Tribunal Regional Federal da Segunda Região-TRF-2 ${ }^{30}$, deixou claro que somente em situações excepcionais é possível suspender a exigência dos tributos. Um dos casos, citados pelo TRF-2, foi o da rede de loja de departamentos Casa e Vídeo. A empresa ajuizou ação na primeira instância requerendo a prorrogação das cobranças de diversos tributos federais, inclusive as referentes a parcelamentos fiscais. O juízo de primeiro grau negou a liminar e, por conta disso, o grupo apresentou agravo no TRF2.

\footnotetext{
${ }^{29}$ BRASIL, Tribunal Regional Federal da Terceira Região, $1^{\text {a }}$ Turma, Agravo de Instrumento $\mathbf{n}^{\mathbf{0}} \mathbf{5 0 0 9 3 2 0 -}$ 66.2020.4.03.0000, Rel. Desembargador Federal Hélio Egydio, julgado em 01/09/2020, disponível em:http://web.trf3.jus.br/base-textual/Home/ListaColecao/9?np=1, acesso em 12/09/2020.

${ }^{30}$ BRASIL, Tribunal Regional Federal da Segunda Região, $1^{\text {a }}$ Turma, Agravo de Instrumento $\mathbf{n}^{\circ}$ 500359611.2020.4.02.0000, Rel. Desembargador Federal Marcus Abraham, julgado em 27/04/2020, disponível em: https://www10.trf2.jus.br/portal/covid-19-trf2-entende-que-prorrogacao-no-pagamento-de-tributos-e-concessaoexcepcional/, acesso em 12/09/2020.
} 
Dentre outros argumentos, a Casa e Vídeo sustentou que a pandemia a impedira de exercer suas atividades, ficando impossibilitada de gerar caixa para honrar compromissos com a Receita. A empresa invocou a Portaria $n^{\circ} 12$, de 20 de janeiro de 2012, do Ministério da Fazenda, que garantiria o adiamento dos vencimentos de tributos em razão de declaração de estado de calamidade pública.

O relator do agravo de instrumento $\mathrm{n}^{\circ}$ 5003596-11.2020.4.02.0000, Desembargador Marcus Abraham, argumentou que estabelecimentos que não prestam serviços essenciais estão com funcionamento suspenso, o que pode impactar no atendimento de obrigações trabalhistas e com fornecedores, mas observou que "empresas de maior porte como a agravante, ainda continuam possibilitadas de oferecer seus produtos e serviços através do comércio on-line, não sendo possível inferir a completa descontinuidade de suas atividades, conforme alegado".

Citando outros precedentes da Terceira e da Quarta Turmas do TRF-2, que também rejeitaram a aplicação da Portaria 12/2012 em razão da pandemia, o desembargador explicou que a norma administrativa foi editada para atender situações enfrentadas por municípios atingidos por enchentes e deslizamentos naquele ano, "cenário completamente diferente do atual”, concluiu.

No caso do Tribunal Regional Federal da Segunda Região-TRF-2 o entendimento caminha no sentido de em regra não admitir a intervenção do Poder Judiciário em políticas de concessão de prorrogação de tributos federais, matéria que está restrita ao Poder Legislativo e não ao Poder Judiciário. Porém, o próprio Tribunal aponta que é possível uma solução distinta a depender do caso concreto.

No Tribunal Regional Federal da Quarta Região-TRF-4 as decisões têm sido ainda mais restritivas, pois nos casos de suspensão de pagamento de tributos federais aquela corte regional entende que o Judiciário não pode atuar como legislador substituindo o Poder Legislativo em seu mister na edição de atos normativos, assim como ao Poder Executivo dentro das hipóteses autorizadas para edição de atos normativos, tais como redução de alíquotas de certos tributos, ou pelas leis, para disciplina mediante decreto autônomo. 
No sentido acima, tratou-se o agravo de instrumento $\mathrm{n}^{\mathrm{o}}$ 5027298-29.2020.4.04.0000/SC ${ }^{31}$, julgado pela Segunda Turma do TRF-4. O Tribunal deixou claro que somente por meio de moratória, devidamente instituída por Lei específica, é possível a suspensão do crédito tributário.

No Tribunal Regional Federal da Primeira Região em pesquisa realizada, há decisões favoráveis aos contribuintes. Cita-se o agravo de instrumento $\mathrm{n}^{\mathrm{o}} 008637-54.2020 .4 .01 .0000^{32}$, cuja relatoria ficou a cargo da Desembargadora Federal Ângela Catão. Neste caso, o juízo de primeira instância indeferiu o pedido de prorrogação, mas o Tribunal Concedeu o pedido de tutela provisória para suspender a exigibilidade do crédito tributário por três meses.

Embora o recurso não tenha sido julgado em seu mérito, no voto da relatora do caso, a mesma argumentou que o cenário de recessão já vivenciado há algum tempo por diversos setores produtivos do país será agravado, afetando sobremaneira a capacidade econômico-financeira das empresas.

Assim, com base na capacidade econômica da sociedade empresária a relatora optou por deferir o pedido de prorrogação do pagamento de tributos federais. Dentre as decisões consultadas, esta foi à única que fez alguma referência à capacidade contributiva da empresa, o que efetivamente deve ser considerado pelo Poder Judiciário em suas decisões.

O que deve a priori pautar a atuação do Judiciário é uma solução de acordo com cada caso em concreto, pois não é possível estabelecer uma solução de maneira uniforme sem se atentar para as particularidades de cada questão. Há situações que realmente impõe uma solução por parte do Poder Judiciário, uma vez que muitas vezes os demais Poderes são omissos em seus deveres constitucionais de tutelar os direitos fundamentais das pessoas.

A regra é realmente aquela que afirma que o Poder Judiciário não pode isentar, prorrogar ou mesmo controlar a carga tributária imposta ao contribuinte, pois tal tarefa cabe primeiramente ao

31 BRASIL, Tribunal Regional Federal da Quarta Região, 2 ${ }^{\mathbf{a}}$ Turma, Agravo de Instrumento 502729829.2020.4.04.0000/SC, Rel. Desembargador Federal Carla Evelise Justino, julgado em 08/09/2020, disponível em: https://jurisprudencia.trf4.jus.br/pesquisa/inteiro_teor.php?orgao=1\&numero_gproc=40001960652\&versao_gproc=4 \&crc_gproc=44cb2833\&termosPesquisados=Y292aWQgdHJpYnV0b3M=, acesso em 13/09/2020.

${ }^{32}$ BRASIL, Tribunal Regional Federal da Primeira Região, Agravo de Instrumento 008637-54.2020.4.01.0000, Rel. Desembargador Federal Ângela Catão, Sétima Turma, julgado em 03/04/2020, disponível em: https://pje2g.trf1.jus.br/consultapublica/ConsultaPublica/DetalheProcessoConsultaPublica/documentoSemLoginHTM L.seam?ca=53f883e45527a593f27cd54584256c644103a16d08a01a7ecb351317e8e09fe2231b56b9b80ec34ea0b5d26d f7e7b534bcb969ba0484f8b3\&idProcessoDoc=50128017, acesso em 13/09/2020. 
Poder Legislativo. Esse inclusive tem sido o entendimento da maioria dos Tribunais Regionais Federais.

A doutrina, segundo José Marcos Domingues de Oliveira, elaborou importante classificação que divide os tributos quanto a sua intensidade, em excessivos, proibitivos e confiscatórios. Os excessivos, embora dificultassem o consumo ou algumas atividades, não poderiam ser objeto de controle jurisdicional, pois somente o legislador poderia atuar neste campo. O tributo proibitivo impossibilitaria ou destruiria qualquer atividade. O tributo confiscatório absorveria importante parcela da propriedade e da renda do contribuinte. Tanto o tributo confiscatório como o proibitivo, poderia merecer controle por parte do Poder Judiciário ${ }^{33}$.

Outra grande problemática ocorreria se várias decisões concedessem prorrogação de tributos federais. Tal situação seria extremamente nefasta ao Estado, pois os tributos são a principal fonte de arrecadação da administração, o que decerto afetaria de maneira extremamente gravosa as atividades essenciais do Estado brasileiro.

O Supremo Tribunal Federal-STF ainda não enfrentou o mérito das situações mencionadas, mas, há um julgado proferido na suspensão de segurança $n^{\circ} 439-\mathrm{SP}^{34}$, na qual o Ministro Dias Toffoli, na qual o Presidente do STF, suspendeu os efeitos de uma decisão proferida pelo Tribunal de Justiça de São Paulo, que concedia a prorrogação de tributos municipais, qual seja ISS.

Em sua decisão, o Ministro Dias Tofolli argumentou que a medida cautelar se limitou a analisar a eventual presença dos requisitos da legislação de regência e concluiu pela verdadeira subversão da ordem tributária vigente no município de Ribeirão Preto, dado que o pedido de suspensão de tributos fosse concedida ela teria o potencial de estender-se a diversas outras empresas, em igual situação tributária, ou mesmo ser replicada para o pagamento de outros tributos, página 3 da

33 OLIVEIRA, José Marcos Domingues de. Direito tributário: capacidade contributiva. 2 ed. Rio de Janeiro: Renovar, 1988, p. 58. A doutrina na visão do autor seriam os seguintes autores: Bernardo Ribeiro de Moraes, Compêndio, cit. P.417/419, Sampaio Dória, Direito Constitucional Tributário e "Due Processo of Law", p.183, Luiz Emygio F. da Rosa Jr, Manual de Direito Financeiro e Direito Tributário, p. 209/210.

${ }^{34}$ BRASIL, Supremo Tribunal Federal, Suspensão de Tutela Provisória no 439-SP, Min. Dias Tofolli, julgado em 19/08/2020, Presidência do STF, disponível portal.stf.jus.br/processos/downloadPeca.asp?id=15344118271\&ext=.pdf, acesso em 13/09/2020. 
decisão.

O Ministro afirmou que não cabe ao Poder Judiciário definir a quem cabe ou não pagar impostos, ou até mesmo quais políticas públicas devem ser adotadas, substituindo os gestores responsáveis pela condução dos destinos do Estado. Disse ainda que apenas eventuais ilegalidades ou violações à ordem constitucional merecem apreciação judicial, pois o Poder Judiciário não foi eleito para tanto e não integra o Poder Executivo, responsável pelo planejamento e execução das políticas públicas, página 4 da decisão.

O Ministro ainda ressaltou que o Judiciário não detém condições técnicas para analisar a melhor solução administrativa para o caso concreto, especialmente quando se trata da questão tributária que afetará sensivelmente o orçamento do Estado, principalmente durante a pandemia em que os gastos com saúde são elevados, desta forma o Ministro suspendeu a decisão do TJ-SP que permitia a prorrogação de tributos.

A decisão do STF é a mesma perfilhada pela maioria dos Tribunais brasileiros, ou seja, a atuação do Judiciário no que diz respeito à suspensão de tributos deve ser evitada, pois cabem aos demais Poderes essa decisão. Contudo, não se pode ignorar que em algumas situações concretas, de maneira excepcional, é possível a atuação do Poder Judiciário para permitir a existência do mínimo existencial e da função social da empresa, com base no princípio constitucional da capacidade contributiva.

\section{CONCLUSÕES.}

De todo o exposto, podem-se extrair algumas considerações sobre a tributação realizada neste período de pandemia. A primeira seria aquela segundo a qual o momento vivenciado no Brasil e no mundo é extremamente excepcional, logo também o direito tributário deve dar o devido tratamento levando em consideração essa situação singular.

A segunda é que o princípio constitucional da capacidade contributiva deve guiar o Estado no momento da cobrança, especialmente quando se está diante de situações onde as pessoas perderam sua capacidade de pagamento e sempre levando em consideração o mínimo existencial e a função social da empresa com o escopo de preservação dos empregos hoje existentes.

A Terceira consideração é aquela que aponta para a utilização de meios consensuais para a solução 
de conflitos no plano da cobrança judicial de tributos, mormente porque serão possíveis concessões recíprocas visando satisfazer as necessidades do Estado e garantir os direitos fundamentais do contribuinte.

A quarta e última observação é que a atuação do Poder Judiciário deva ser cautelosa e com o mínimo de interferência possível, pois somente os demais Poder dispõe de capacidade técnica para avaliar o que é melhor para o Estado. Todavia, isso não impede que, em determinadas situações excepcionais, onde o mínimo vital do individuo e a função social da empresa esteja em risco, o Poder Judiciário possa intervir para corrigir uma distorção ou omissão presente na relação jurídico-tributária.

\section{REFERÊNCIAS.}

ANDRADE, José Carlos Vieira de. Direito administrativo e fiscal. Coimbra: Faculdade de Direito, 1995, p. 17.

BRASIL, Planalto, Decreto- Legislativo $n^{\circ} 6$ de 2020, Reconhece o Estado de Calamidade Pública. Disponível em: http://www.planalto.gov.br/ccivil_03/portaria/DLG6-2020.htm. Acesso em: 01 setembro de 2020.

BRASIL, Câmara dos Deputados, Projeto de Lei Complementar de no 34/, Disponível em: https://www.camara.leg.br/proposicoesWeb/prop_mostrarintegra;jsessionid=10E1BF8BF4B47514 6373026775F4331B.proposicoesWebExterno1? codteor=1869953\&filename $=P L P+34 / 2020$. Acesso em 04 setembro de 2020.

BRASIL, Planalto, Lei $\mathbf{n}^{\mathbf{0}} \mathbf{5 . 1 7 2 / 6 6}$ (Código Tributário Nacional), disponível em: http://www.planalto.gov.br/ccivil_03/leis/15172compilado.htm, acesso em 09/09/2020.

BRASIL, Planalto, Lei $\mathbf{n}^{\mathbf{0}}$ 13.988/2020 (Lei de Transação Tributária), disponível em: http://www.planalto.gov.br/ccivil_03/_ato2019-2022/2020/lei/113988.htm, acesso em 09/09/2020.

BRASIL, Planalto, Portaria PGFN n 9.917/2020 (Regulamenta a transação na cobrança da dívida ativa da União), disponível em: http://normas.receita.fazenda.gov.br/sijut2consulta/link.action?visao=anotado\&idAto=108608, acesso em 09/09/2020.

BRASIL, Planalto, Portaria PGFN no 9.924/2020 (Regulamenta a transação extraordinária na cobrança da dívida ativa da União, em função da pandemia causada pelo coronavirus), disponível em: http://normas.receita.fazenda.gov.br/sijut2consulta/link.action?visao=anotado\&idAto=108609.

BRASIL, Tribunal de Contas da União, Relatório de Acompanhamento n ${ }^{\circ}$ TC 016.841/2020-4, Acompanhamento especial das medidas de resposta à crise do coronavírus na arrecadação

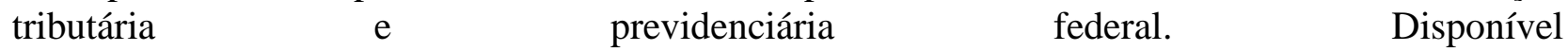


em:https://pesquisa.apps.tcu.gov.br/\#/documento/acordaocompleto/1684120204.Acesso em 01 setembro de 2020.

BRASIL, IBGE, indicadores de empresas, Disponível em: https://covid19.ibge.gov.br/pulsoempresa/. Acesso em 04 de setembro de 2020.

BRASIL, Tribunal Regional Federal da Terceira Região, $1^{\text {a }}$ Turma, Agravo de Instrumento $\mathbf{n}^{\mathbf{o}}$ 5009320-66.2020.4.03.0000, Rel. Desembargador Federal Hélio Egydio, julgado em 01/09/2020, disponível em:http://web.trf3.jus.br/base-textual/Home/ListaColecao/9?np=1, acesso em $12 / 09 / 2020$.

BRASIL, Tribunal Regional Federal da Segunda Região, $1^{\text {a }}$ Turma, Agravo de Instrumento $\mathbf{n}^{\mathbf{0}}$ 5003596-11.2020.4.02.0000, Rel. Desembargador Federal Marcus Abraham, julgado em 27/04/2020, disponível em: https://www10.trf2.jus.br/portal/covid-19-trf2-entende-queprorrogacao-no-pagamento-de-tributos-e-concessao-excepcional/, acesso em 12/09/2020.

BRASIL, Tribunal Regional Federal da Quarta Região, 2 ${ }^{\mathrm{a}}$ Turma, Agravo de Instrumento 5027298-29.2020.4.04.0000/SC, Rel. Desembargador Federal Carla Evelise Justino, julgado em 08/09/2020, disponível

em: https://jurisprudencia.trf4.jus.br/pesquisa/inteiro_teor.php?orgao $=1 \&$ numero_gproc $=40001960652$

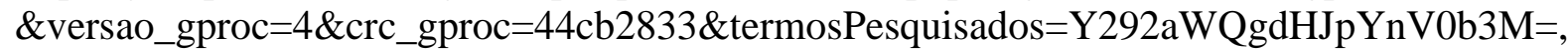
acesso em 13/09/2020.

BRASIL, Tribunal Regional Federal da Primeira Região, Agravo de Instrumento 00863754.2020.4.01.0000, Rel. Desembargador Federal Ângela Catão, Sétima Turma, julgado em 03/04/2020, disponível em: https://pje2g.trf1.jus.br/consultapublica/ConsultaPublica/DetalheProcessoConsultaPublica/docume ntoSemLoginHTML.seam?ca=53f883e45527a593f27cd54584256c644103a16d08a01a7ecb35131 7e8e09fe2231b56b9b80ec34ea0b5d26df7e7b534bcb969ba0484f8b3\&idProcessoDoc=50128017, acesso em 13/09/2020.

BRASIL, Supremo Tribunal Federal, Suspensão de Tutela Provisória n 439-SP, Min. Dias Tofolli, julgado em 19/08/2020, Presidência do STF, disponível em: portal.stf.jus.br/processos/downloadPeca.asp?id=15344118271\&ext=.pdf, acesso em 13/09/2020.

BECKER, Alfredo Augusto. Teoria geral do direito tributário. 2.ed. São Paulo: Saraiva, 1972, p.439.

BALEEIRO, Aliomar. Direito Tributário Brasileiro. 12. ed. rev., atual. e ampl. (atualizada por MisabelAbreu Machado Derzi). Rio de Janeiro: Forense, 2013, p. 1324-1325.

COÊLHO, Sacha Calmon Navarro. Curso de direito tributário. 7. ed. Rio de Janeiro: Forense, 2004 , p. 85.

CARRAZZA, Roque Antônio. Imposto sobre a renda: perfil constitucional e temas específicos.

2. ed. São Paulo: Malheiros, 2006, p.313. 
BECKER, Alfredo Augusto. Teoria geral do direito tributário. 2.ed. São Paulo: Saraiva, 1972, p.439.

DÓRIA, Antônio Roberto Sampaio. Direito constitucional tributário e “due process of law". Rio de Janeiro: Forense, 1986, p. 182.

JUNIOR, Edilson Pereira Nobre. Princípio constitucional da capacidade contributiva. Porto Alegre: Sergio Antonio Fabris, 2001, p.13.

NOGUEIRA, Pedro Henrique, Negócios jurídicos processuais, Salvador-Ba, 2016, Ed. Juspodvm, p.225.

OLIVEIRA, José Marcos Domingues de. Direito tributário: capacidade contributiva. 2 ed. Rio de Janeiro: Renovar, 1988, p. 58.

RODRIGUES, Silvio, Direito civil: dos contratos e das declarações unilaterais da vontade. São Paulo: Saraiva, 2004, v. 3, p. 368.

SANTOS, Boaventura de Sousa. Por uma concepção multicultural de direitos humanos. Rio de Janeiro: Civilização Brasileira, 2003, p.433.

TIPKE, Klaus. Moral tributaria del estado e de lós contribuyentes. Madrid: Marcial Pons, 2002, p.27. 